\title{
Study of the photocatalytic degradation of methylene blue dye using titanium-doped hydroxyapatite
}

\author{
Anas Salhi 1,*, Abdellatif Aarfane ${ }^{1}$, Soufiane Tahiri ${ }^{1}$, Layachi Khamliche ${ }^{2}$, Mohammed Bensitel ${ }^{3}$, \\ Fouad Bentiss ${ }^{3}$ and Mohammed El Krati ${ }^{1}$ \\ ${ }^{1}$ Laboratory of Water and Environment, Department of Chemistry, Faculty of Sciences, \\ University Chouaïb Doukkali, PO. Box 20, El Jadida 24000, Morocco \\ ${ }^{2}$ Laboratory of Organic Chemistry, Biochemistry and Environment, Department of Chemistry, Faculty of Sciences, \\ University Chouaïb Doukkali, PO. Box 20, El Jadida 24000, Morocco \\ ${ }^{3}$ Laboratory of Catalysis and Corrosion of Materials, Department of Chemistry, Faculty of Sciences, \\ University Chouaïb Doukkali, PO. Box 20 El Jadida 24000, Morocco
}

\begin{abstract}
Organic dyes and colouring textile agents are persistent pollutant materials that are difficult to decompose by microbiological treatment processes. Their oxidation through photocatalysis is an alternative way to prevent contamination of the environment. In this work, calcium deficient hydroxyapatite (HAP) was synthesized and doped with different amounts of titanium. Its performance in photocatalytic degradation of - methylene blue dye (MB) was then demonstrated. The main parameters which govern the photocatalytic treatment efficiency, such as doped titanium amount, $\mathrm{pH}$, initial concentration of $\mathrm{MB}$, weight of catalyst added to solution, UV-irradiation period and bubbling oxygen- have been- investigated. Photodegradation of MB is found to be effective with HAP/11 wt. \% Ti in oxygenated medium. However, $\mathrm{pH}$ has no significant effect on the yield of discoloration.
\end{abstract}

Keywords: Photodegradation; Ti-doped HAP; UV-irradiation; Methylene bleu.

\section{Introduction}

The textile dyeing industry consumes large quantities of water and produces consequently large volumes of wastewaters which are responsible for many environmental damages and impacts ${ }^{1}$. Textile effluents contain organic and inorganic chemical species that have harmful effect on the human health and environment. Organic dyes or colouring agents are persistent pollutants and not readily biodegradables because of the complexity of their chemical structures ${ }^{2,5}$. Concentrations of these pollutants in the effluents should be controlled in order to respect environment norms and legislation on water quality which become more stringent in recent years ${ }^{6}$.

Treatment of dyed textile effluents is a major challenge especially for developing countries. Management of these wastewaters requires specific treatment techniques such as activated carbon adsorption ${ }^{7,9}$, membrane processes $^{10}$, coagulation-flocculation ${ }^{11}$, reverse osmosis, chemical oxidation or reduction ${ }^{12-17}$, etc. The Advanced Oxidation Processes (AOPs) show specific advantages over conventional treatments because they can eliminate non-biodegradable

* Corresponding author: Anas Salhi

Email address: anassalhi@hotmail.com

DOI: http://dx.doi.org/10.13171/mjc.4.1.2015.16.01.20.30/salhi 
organic components and avoid the need to dispose of residual sludge. AOPs based on the generation of very reactive and oxidizing free radicals, especially hydroxyl radicals, have been used with an increasing interest due to their high oxidant power ${ }^{18,19}$.

Calcium hydroxyapatites are very thermally stable products; they are handled as harmless solids to the environment and not soluble in water ${ }^{20}$. HAP is one of the most important bioceramics for medical and dental application such as bone reconstruction and drug delivery systems $^{21,22}$. Recently, HAP has been found to be applied in the adsorption of bacteria, virus, $\mathrm{NO}_{\mathrm{x}}$ and ammonia ${ }^{23,24}$. It is also used industrially in sensors, fluorescence materials, chromatography and environmental phosphorus recovery ${ }^{25}$. As a catalyst, HAP has the unusual property of containing both acid and basic sites in a single crystal lattice ${ }^{25-28}$.

In this work, we studied the discoloration of MB by heterogeneous catalysis. First, deficient hydroxyapatite (HAP) was synthesized and doped with different amounts of titanium. We have then studied its performance in the photocatalytic degradation of methylene blue dye. Discoloration tests were carried out in a photocatalytic reactor under different operational conditions such as titanium percentage in HAP, $\mathrm{pH}$, catalyst weight, initial concentration of dye, bubbling of oxygen and contact time.

\section{Experimental Section}

\section{Preparation of calcium deficient hydroxyapatite HAP}

Two solutions "A" and "B" were used for the preparation of a calcium deficient apatite: Solution $\mathrm{A}$ is obtained by dissolving $18.9 \mathrm{~g}$ of calcium nitrate tetrahydrate in $100 \mathrm{~mL}$ of demineralized water. The solution $\mathrm{B}$ was prepared by adding $100 \mathrm{~mL}$ of ammonia in $11.7 \mathrm{~g}$ of ammonium hydrogen phosphate in one liter of deionized water. With a dropping funnel, the solution "A" was added dropwise over 3 hours to the ammoniacal solution "B" heated to $80^{\circ} \mathrm{C}$ under stirring. The $\mathrm{pH}$ of the solution was monitored regularly to keep a value close to 9. Once the addition was complete, the solution is stirred for an additional $30 \mathrm{~min}$ at $80{ }^{\circ} \mathrm{C}$. A hot filtration was then performed and the precipitate obtained was washed by the use of hot distilled water to remove nitrates. Finally, the precipitate was placed in a pyrex vessel and was heated in an oven at $60{ }^{\circ} \mathrm{C}$ overnight ${ }^{20}$. The chemical elemental analysis of the obtained compound indicates that it is a deficient apatite with a Ca/P ratio of about 1.50 , a specific area of $80 \mathrm{~m}^{2} / \mathrm{g}$ and a pore volume of $0.34 \mathrm{~mL} / \mathrm{g}$.

\section{Doping of HAP with titanium isopropoxide}

To a definite amount of HAP, we added titanium (IV) isopropoxide ( $\left.\mathrm{Ti}(\mathrm{OiPr})_{4}\right)$ so as to have a doped catalyst with $3 \%, 6 \%$ and $11 \%$ of Ti. The mixture was then calcined in a furnace (LabTech LEF-203P) at $450{ }^{\circ} \mathrm{C}$ for 4 hours and $30 \mathrm{~min}$. Before its use, titanium-doped hydroxyapatite was first characterized by X-ray diffraction, infrared spectroscopy and elemental analysis as described in our previous work ${ }^{29}$. X-ray powder diffraction (XRD) showed the presence of peaks corresponding to the apatite and other attributed to the titanium dioxide anatase $\mathrm{TiO}_{2}$. The peak intensity of the titanium is proportional to its used quantity. The percentages of $\mathrm{Ca}, \mathrm{Ti}, \mathrm{O}$ and $\mathrm{P}$ in the catalyst show a $\mathrm{Ca} / \mathrm{P}$ ratio of about $1.56^{29}$.

The chemical composition of the powders was measured by using a Scanning Electron Microscope Hitachi S340N equipped with an Energy Dispersive X-rays Spectrometer (EDS). The energy of the acceleration beam employed was $15 \mathrm{kV}$. Prior to analysis, the sample was 
carbon coated with a Bal-Tec SCD005 sputter coater. The obtained results shown in Fig.1 clearly reveal the presence of titanium in the final synthesized material.
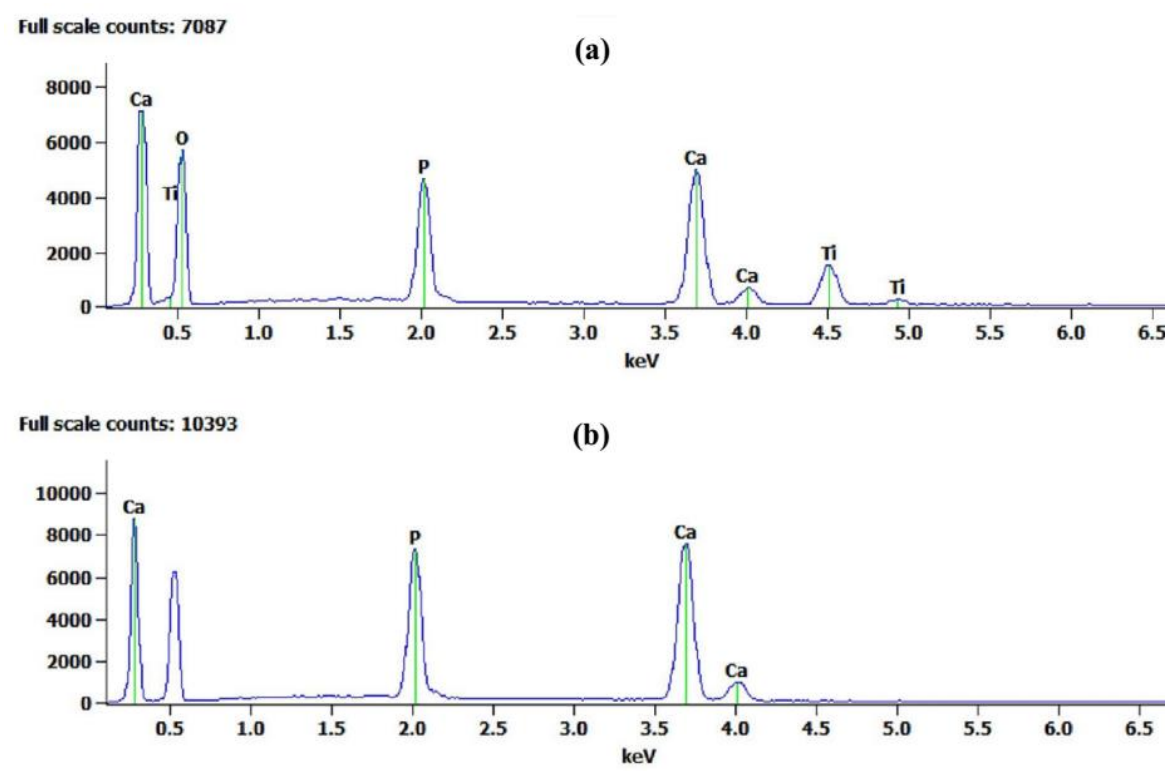

Figure 1. EDS analysis of (a) HAP/11 wt. \%Ti and (b) Titanium free HAP

\section{Photoreactor and light sources}

The photocatalytic reactor is a cylindrical stainless metal (Figure 2), equipped with 3 UVA lamps and 3 UVB lamps ( 8 watts, $\lambda: 300-450 \mathrm{~nm}$ ). The solution to be irradiated was introduced in a Pyrex tube placed in the center of the reactor by means of clamp system. At the bottom, the unit is cooled by a fan to prevent evaporation of solution. The homogeneity of the solution is ensured through agitation, using a bubbler which allows also the aeration of the medium to be treated.

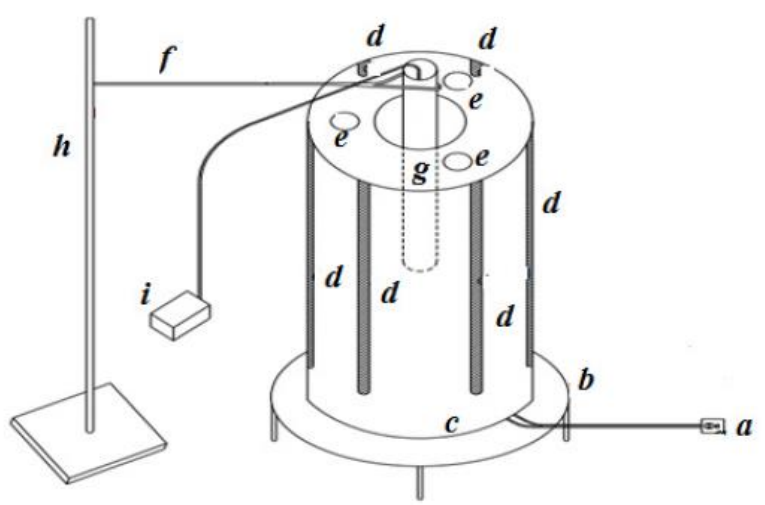

Figure 2. Simplified scheme of the photoreactor.

(a) Power supply cable, (b) Support of reactor, (c) Fan, (d) Lamps,

(e) Aeration holes, (f) Clamp, (g) Pyrex tube, (h) Support, and (i) Air bubbler.

\section{Studied dye}

Photodegradation of methylene blue (MB) was studied to assess the effectiveness of the catalyst prepared in the context of this work. Methylene blue (CI 52015) is a heterocyclic aromatic chemical compound (Figure 3) with the molecular formula $\mathrm{C}_{16} \mathrm{H}_{18} \mathrm{~N}_{3} \mathrm{SCl}$ corresponding to a molecular weight of $319.7 \mathrm{~g} . \mathrm{mol}^{-1}$. It is a cationic dye molecule belonging to the Xanthines family. Its wavelength of maximum absorption is $664 \mathrm{~nm}$. 
<smiles></smiles>

Figure 3. Chemical structure of methylene blue dye

\section{Photodegradation test}

$20 \mathrm{~mL}$ of a solution of methylene blue dye, with a concentration of $10 \mathrm{mg} / \mathrm{L}$, are introduced in the Pyrex tube of the photoreactor in the presence of $10 \mathrm{mg}$ of HAP/Ti $(0.5 \mathrm{~g}$ of the support per liter of solution). First, the mixture was stirred for $30 \mathrm{~min}$ in the dark to reach adsorption equilibrium on the solid surface. The mixture was then UV-irradiated and monitored for 4 hours. Samples were taken every $30 \mathrm{~min}$ and centrifuged with a speed of $4000 \mathrm{rpm} / \mathrm{min}$ for $2 \mathrm{~min}$. The absorbance of the solution was then measured at $664 \mathrm{~nm}$, by the use of a spectrophotometer (Shimadzu $3600 \mathrm{UV/Visible),} \mathrm{before} \mathrm{being} \mathrm{returned} \mathrm{to} \mathrm{the} \mathrm{reactor.}$

\section{Results and discussion}

\section{Effect of titanium percentage}

In order to reveal the effect of the amount of titanium introduced in HAP, a methylene blue solution at $10 \mathrm{mg} / \mathrm{L}$ was UV-irradiated in the presence of the catalysts HAP/3 wt. \% Ti, HAP/6 wt. \% Ti and HAP/11 wt. \% Ti. Another solution of MB at $10 \mathrm{mg} / \mathrm{L}$, considered as reference, was irradiated in the presence of free HAP titanium. The results given in Figure 4 show that UVirradiation of methylene blue solution in the presence of free titanium HAP has no remarkable effect. As we can notice, the discoloration via calcium deficient hydroxyapatite (undoped HAP) is very low. The degradation efficiency does not exceed $5 \%$ after $4 \mathrm{~h}$ of treatment. However, the efficiency of degradation becomes very important by the use of titanium-doped hydroxyapatite as a photocatalyst. As can be seen, the photodegradation improves as the amount of doped titanium increases. For example, after $4 \mathrm{~h}$ of UV-irradiation, the yields of discoloration can reach $77 \%, 83 \%$ and $93 \%$ when HAP/3 wt. $\%$ Ti, HAP/6 wt. $\%$ Ti and HAP/11 wt. $\%$ Ti are used, respectively.

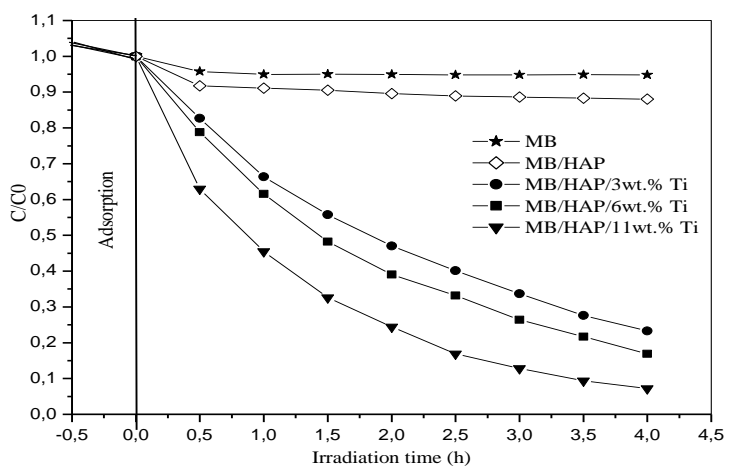

Figure 4. Kinetics of the degradation of methylene blue dye in the presence of free titanium HAP and HAP doped with different amounts of titanium (volume : $20 \mathrm{~mL}$, weight : $10 \mathrm{mg}$, dye concentration: $10 \mathrm{mg} / \mathrm{L}$ )

These experiments allowed us to highlight the effect of titanium percentage on the speed of discoloration of MB solution under UV-irradiation. The obtained results are shown in Table 1. We found that the degradation speed varies in the same sense of the amount of titanium in HAP. 
As shown, the kinetic constant increases from $0.079 \mathrm{~h}^{-1}$ to $0.204 \mathrm{~h}^{-1}$ when the percentage of titanium in HAP increases from $0 \%$ to $11 \%$.

Table 1. Kinetic constant of photodegradation of methylene blue as a function of the doped amount of titanium.

\begin{tabular}{lcccc}
\hline & Titanium free HAP & HAP/3 wt. \%Ti & HAP/6 wt. \% Ti & HAP/11 wt. \% Ti \\
\hline $\mathrm{k}\left(\mathrm{h}^{-1}\right)$ & 0.079 & 0.184 & 0.196 & 0.204 \\
\hline
\end{tabular}

\section{Effect of pH}

Several authors have studied the effect of $\mathrm{pH}$ on the degradation of pollutants by catalyzed oxidation and have shown that $\mathrm{pH}$ is a parameter that affects the efficiency of the photocatalytic discoloration process ${ }^{30,31}$. In our case, methylene blue solutions $(10 \mathrm{mg} / \mathrm{L})$ with $\mathrm{pH}$ values of 3 , 6 and 10 were UV-irradiated during 3 hours in the presence of $10 \mathrm{mg}$ of HAP/11 wt. \% Ti in order to show the effect of this parameter on the degradation of MB dye. The results obtained show that $\mathrm{pH}$ did not significantly influence the photocatalytic performance (Figure 5). As it can be seen, the yields of discoloration at the end of three hours are around $87 \%, 91 \%$ and $92 \%$ respectively in the neutral, acidic and basic media. This result is similar to that observed by Lanhua et al ${ }^{32}$.

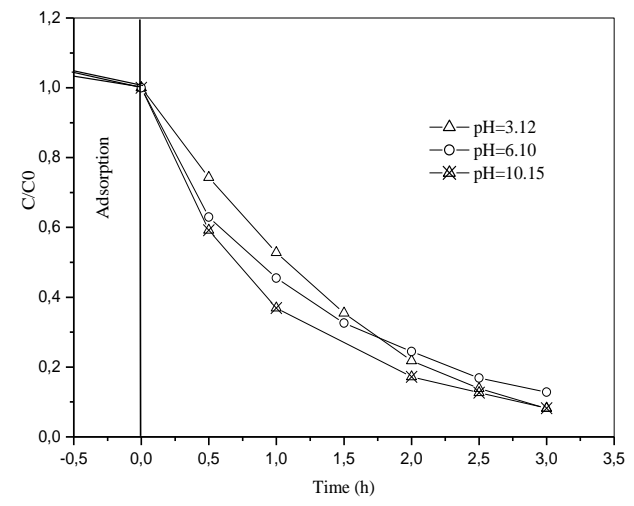

Figure 5. Effect of $\mathrm{pH}$ on the photocatalytic degradation of methylene blue (volume: $20 \mathrm{~mL}$, dye concentration: $10 \mathrm{mg} / \mathrm{L}, \mathrm{HAP} / 11 \mathrm{wt}$. $\% \mathrm{Ti}: 10 \mathrm{mg}$ )

\section{Effect of the amount of HAP/11 wt. \% Ti}

To optimize the amount of the photocatalyst needed for the best possible performance, a series of experiments were conducted by increasing the weight of HAP/11 wt. \% Ti from 0 to $2 \mathrm{~g} / \mathrm{L}$. Figure 6 illustrates the evolution of the kinetic constant of photodegradation of methylene blue as a function of the weight of HAP/11 wt. \%Ti. As we can see the kinetic constant is strongly dependent on the amount of titanium doped-HAP. We observe an improvement of the discoloration by increasing the catalyst mass. This can be explained by the availability of more active sites on the surface of the tested photocatalys $\mathrm{t}^{33,34}$. When the concentration of HAP/11 wt. $\% \mathrm{Ti}$ in solution reached $1 \mathrm{~g} / \mathrm{L}$, the degradation rate remains constant. If the amount of photocatalyst exceeds the proper value of $1.5 \mathrm{~g} / \mathrm{L}$, the screening effect becomes dramatic. This masks part of the sensitive surface and consequently, degradation efficiency is reduced. A similar phenomenon has also been reported by other authors such as Chen et al ${ }^{35}$, and Zhao et al 36. At high concentrations of the photocatalyst, the aggregation of particles can occur and may cause a decrease in the number of surface active sites ${ }^{37}$. 


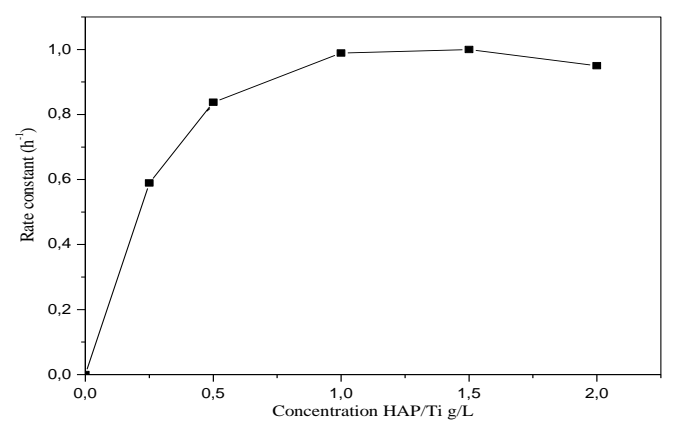

Figure 6. Kinetic constant vs. HAP/11 wt. \% Ti weight.

(volume : $20 \mathrm{~mL}$, dye concentration: $10 \mathrm{mg} / \mathrm{L}$ )

\section{Effect of initial dye concentration}

The initial concentration is one of the parameters that affect the performance of discoloration. Three concentrations of MB (10, 20 and $30 \mathrm{mg} / \mathrm{L})$ were studied in this work. A mass of $10 \mathrm{mg}$ of HAP/11 wt. \% Ti was added to each solution and the mixtures were UV-irradiated for $4 \mathrm{~h}$. The obtained results are shown in Figure 7. The inspection of these results clearly shows that discoloration performance is strongly influenced by the initial concentration of MB solution. For a weight/volume ratio of $0.5 \mathrm{~g} / \mathrm{L}$, the yield of dye removal decreases by increasing dye concentration. It can reach $93 \%, 61 \%$ and $27 \%$ when MB concentration is 10, 20 and $30 \mathrm{mg} / \mathrm{L}$, respectively. This appears quite normal because the number of $\mathrm{MB}$ molecules to be degraded is more important for solutions with high concentrations. Sakthivel et al. ${ }^{38}$ have explained the effect of the initial concentration as follow: by increasing dye concentration, more and more organic matters are adsorbed on the photocatalyst surface. However, the intensity of light, ${ }^{\bullet} \mathrm{OH}$ and $\mathrm{O}_{2}^{2-\bullet}$ formed on the surface is constant. The relative number of ${ }^{\bullet} \mathrm{OH}$ and $\mathrm{O}_{2}^{2-\bullet}$ which attack MB molecules decreases and the photodegradation activity also decreases.

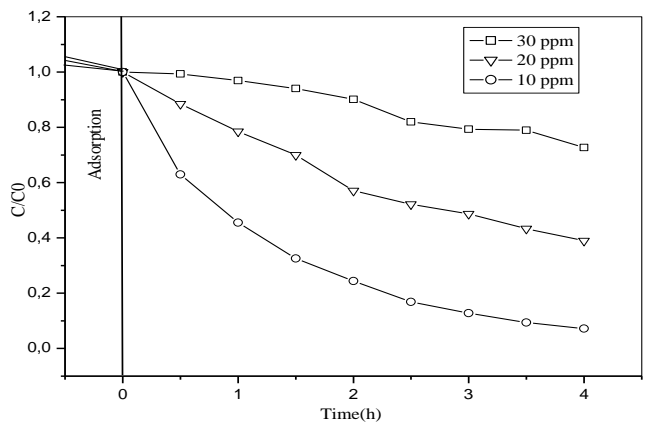

Figure 7. Photocatalytic degradation of $\mathrm{MB}$ at different irradiation times as a function of its initial concentration (volume: $20 \mathrm{~mL}, \mathrm{HAP} / 11 \mathrm{wt}$. \%Ti: $10 \mathrm{mg}$ )

\section{Effect of bubbling oxygen}

In order to determine the influence of bubbling oxygen on the photocatalytic efficiency, MB photodegradation was performed by bubbling oxygen through an aqueous suspension containing $10 \mathrm{mg}$ of dye and $0.5 \mathrm{~g}$ of catalyst per liter of solution. Moreover, photodegradation in deoxygenated medium was carried out after removal of oxygen by bubbling nitrogen for $20 \mathrm{~min}$ before closing the reactor by a septum to avoid any exchange with the external environment. From the obtained results presented in Figure 8, we note that the performance of discoloration is higher in the oxygenated environment than in the non-oxygenated medium. Indeed, the yield of degradation of MB dye in the presence of oxygen is much larger (93\%) than in the oxygen-free environment (61\%). 


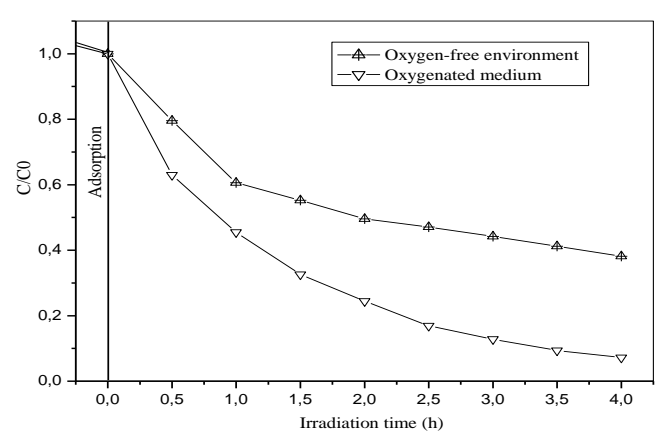

Figure 8. Degradation of $\mathrm{MB}$ as a function of irradiation time in oxygenated and deoxygenated aqueous medium (volume: $20 \mathrm{~mL}$, dye concentration: $10 \mathrm{mg} / \mathrm{L}, \mathrm{HAP} / 11 \mathrm{wt}$ \% $\% \mathrm{Ti}: 10 \mathrm{mg}$ )

This result appears quite logical since during the photochemical oxidation process, the emitted radiation can directly lead to the transformation of the target pollutant. For example, an organic pollutant (R) is first photo-excited (eq. 1), subsequently it may react with oxygen dissolved in water (eq.2) and then leads to the formation of sub-products (eq.3) ${ }^{39}$.

$$
\begin{array}{ll}
\mathrm{hu} & \\
\mathrm{R} & \mathrm{R}^{*} \\
\mathrm{R}^{*} \rightarrow \mathrm{R}^{\circ+}+\mathrm{O}_{2}^{-{ }^{\circ}} & \text { (eq. } 2) \\
\mathrm{R}^{\circ+} \rightarrow \text { Product } & \text { (eq.3) }
\end{array}
$$

\section{Effect of irradiation time on visible absorption spectrum}

With the aim to show the effect of irradiation time on MB degradation, in the presence of HAP/11 wt. \%Ti, the evolution of its visible absorption spectrum was monitored during $10 \mathrm{~h}$. The samples were taken and analyzed periodically each $2 \mathrm{~h}$. The recorded absorption spectra are shown in Figure 9. As it can be seen, UV-irradiation of MB solution in the presence of the tested catalyst (HAP/11 wt. \%Ti) leads to a decrease in the intensity of the absorption spectrum. An irradiation period of about $8 \mathrm{~h}$ is more than enough to reach an almost complete discoloration of the MB dyed solution.

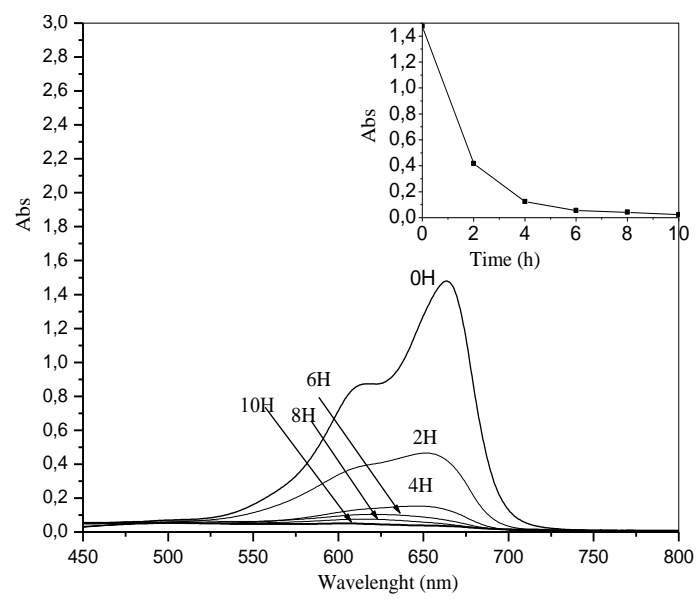

Figure 9. Evolution of the visible absorption spectrum of MB solution as a function of irradiation time (volume: $20 \mathrm{~mL}$, dye concentration: $10 \mathrm{mg} / \mathrm{L}, \mathrm{HAP} / 11 \mathrm{wt}$ \% $\%$ Ti: $10 \mathrm{mg}$ ). 


\section{Conclusions}

This study clearly shows efficient photodegradation of methylene blue dye using titanium doped hydroxyapatite as catalyst in aqueous suspension. Our work attempts to demonstrate the capabilities of HAP/11 wt. \% Ti to degrade MB and to show the effect of some parameters on the treatment efficiency. The analysis of the results obtained allows us to conclude that HAP/11 wt. $\% \mathrm{Ti}$ is photocatalytically active under UV light. A ratio catalyst/solution of about $1 \mathrm{~g} / \mathrm{L}$ is recommended to reach a maximum discoloration of the synthetic $\mathrm{MB}$ solution at $10 \mathrm{mg} / \mathrm{L}$. The $\mathrm{pH}$ does not have a significant influence on the photodegradation of MB solution; the treatment performance is almost the same for acidic, neutral and basic mediums. Furthermore, the obtained results show that the oxygen affects positively the photocatalytic discoloration.

\section{References}

1- S. Bouafia, Degradation of textile dyes by advanced oxidation processes based on fenton reaction, application to the depollution of industrial effluents. Thèse de l'Université de Paris-Est (France) et de l'Université Saâd Dahlab (Algérie) 2010.

2- D. Brown, P. Laboureur, Chemosphere 1983, 12, 397-404.

3- J-S. Chang, Y-C. Lin, Biotechnology Progress 2000, 16, 979-985.

4- T. Robinson, G. McMullan, R. Marchant, P. Nigam, Bioresource Technology 2001, 77, 247-255.

5- S.A. Figueiredo, J.M. Loureiro, R.A. Boaventura, Water Research, 2005, 39, 4142-4152.

6- H.P. Boehm, Chemical identification of surface groups. In Advances in Catalysis 16, New York: Academic Press 1966, p.179-274.

7- S.D. Lambert, N.J.D. Graham, C.J. Sollars, G.D. Fowler, Water Sci. Technol. 1997, 36, 173-180.

8- S.H. Lin, J. Chem. Technol. Biotechnol. 1993, 57, 387-391.

9- K.R. Ramakrishna, T. Viraraghavan, J.Water Sci. Technol. 1997, 36, 189-196.

10- J.S. Taylor, E.P. Jacobs, Reverse osmosis and nanofiltration, In Water Treatment Membrane Processes, eds J. Mallevialle, P. E. Odendaal and M. R. Wiesner, pp. 9.1-9.70. Mc Graw Hill, New York, NY, 1996.

11- S. Papic, N. Koprivanac, A.L.C. Bozic, Color. Technol. 2000, 116, 352-358.

12- P. Cooper, Color in dye house effluent, in: Society of dyes and colourists, Alden Press, Oxford 1995, p. 9.

13- E.J. Weber, R.L. Adams, Environ. Sci. Technol. 1995, 29, 1163-1170.

14- W.Z. Tang, R.Z. Chen, Chemosphere 1996, 32, 947-958.

15- R. Liu, H. Tang, J. Wat. Res. 2000, 34, 4029-4035.

16- N. Deng, F. Luo, F. Wu, M. Xiao, X. Wu, J. Wat. Res. 2000, 34, 2408-2411.

17- S. Hammami, Etude de dégradation des colorants de textile par les procédés d'oxydation avancée. Application à la dépollution des rejets industriels, Doctorat de l'Université Paris-Est et de l'Université de Tunis El Manar 2008.

18- K. Kestioglu, T. Yonar, N. Azbar, Process Biochemistry 2005, 40, 2409-2416.

19- T. Yonar, Decolorisation of textile dyeing effluents using advanced oxidation processes, advances in treating textile effluent, Prof. Peter Hauser (Ed.), ISBN: 978-953-307-704-8, InTech. 2011. 
20- C. Lamonier, J.F. Lamonier, B. Aellach, A. Ezzamarty, J. Leglise. J. Catalysis Today 2011, 164, 124-130.

21- K.J.L. Burg, S. Porter, J.F. Kellam, Biomaterials 2000, 21, 2347-2359.

22- E. Mavropoulos, A.M. Rossi, N.C.C. da. Rocha, G.A. Soares, J.C. Moreira, G.T. Moure, Materials Characterization. 2003, 50, 203-207.

23- Y. Watanabe, Y. Moriyoshi, Y. Suetsugu , T. Ikoma, T. Kasama, T. Hashimoto, H. Yamada, J. Tanaka, J. Am. Ceram. Soc. 2004, 87, 1395-1397.

24- K. Elkabouss, M. Kacimi, M. Ziyad, S. Ammar, F. Bozon-Verduraz, J. Catal 2004, 226, $16-24$.

25- T. Tsuchida, J. Kubo, T. Yoshioka, S. Sakuma, T. Takeguchi, W. Ueda, Journal of Catalysis. 2008, 259, 183-189.

26- N.S. Resende, M. Nele, V.M.M. Salim, Thermochim. Acta. 2006, 45, 16-21.

27- N. Elazarifi, A. Ezzamarty, J. Leglise, L.C. Menorval, C. Moreau, Appl. Catal. A Gen. 2004, 267, 235-240.

28- A. Venugopal, M.S. Scurrell, Appl. Catal. A Gen. 2003, 245, 137-147.

29- A. Salhi, A. Aarfane, S. Tahiri, L. Khamliche, M. Bensitel, S. Rafqah, N. Benzidia, M. El Krati. J. Mater. Environ. Sci. 2014, 5, 1573-1582.

30- W. Chu, W.K. Choy, T.Y. So, Journal of Hazardous Materials 2007, 141, 86-91.

31- S. Rafqah, P. Wong-Wah-Whung, C. Forano, M. Sarakha, Journal of Photochemistry and Photobiology A: Chemistry 2008, 199, 297-302.

32- H. Lanhua, P.M. Flanders, P.L. Miller, T.J. Strathmann, J. Wat. Res. 2007, 41, 2612-2626.

33- K. Soutsas, V. Karayannis, L. Poulios, A. Riga, K. Ntampegliotis, X. Spiliotis, G. Papapolymerou, Desalination 2010, 250, 345-350.

34- M. Muruganandham, M. Swaminathan, Sol. Energy Mater. Sol. Cells 2004, 81, 439-457.

35- D. Chen, J. Zhong, Y. Wang, Fine Chem. 2002, 1, 55-58.

36- H. Zhao, S. Xu, J. Zhong, X. Bao, Catalysis Today 2004, 93-95, 857-861.

37- S. Fassi, K. Djebbar, T. Sehili, J. Mater. Environ. Sci. 2014, 5, 1093-1098.

38- S. Sakthivel, B. Neppolian, B. Arabindoo, M. Palanichamy, V. Murugesan, Journal of Scientific \& Industrial Research 2000, 59, 556-562.

39- F. Zaviska, P. Drogui, G. Mercier, J .F. Blais, Rev. Sci. Eau. 2009, 22, 535-564. 